Book Reviews / Comptes rendus de livres

\title{
Kylie Hutchinson, ed. (2018). Evaluation Failures: 22 Tales of Mistakes Made and Lessons Learned. Thousand Oaks, CA: SAGE. Paperback, 159 pages. (ISBN: 978-1-5443-2000-7)
}

\section{Reviewed by Oralia Gómez-Ramírez, University of British Columbia}

Evaluation Failures is an edited volume detailing the tribulations and hard-earned lessons of 23 evaluation professionals. Kylie Hutchinson has compiled a compelling page-turner whose self-reflective spirit can be summarized as an antidote to full-blown failure.

Divided into eight parts, the book takes the reader along a typical evaluation cycle, from managing the evaluation and defining stakeholders to reporting useful findings. Each chapter uses a conversational tone and is structured in an easily digestible format: an enticing snippet that situates the reader at the heart of the sticky situation, a note about the evaluator, a description of the project and discussion of the challenge or mistake, the lessons learned, and a set of reflective questions. Sprinkled with colourful titles capturing the difficulties being discussed, photos of the evaluators, and cartoons of their troubles, this is a well-conceived collection.

The chapters reflect six types of challenge. First, there are challenges resulting from the failure to assess a project's undercurrents. Jara Dean-Coffey discusses how her dreams of building evaluation capacity were crushed when she realized there was no readiness to engage in such a task. Jennifer Bisgard and Mary Pat Selvaggio went into a project hoping to assess its impact but overestimated the commitment toward evaluation and underestimated the sensitive nature of data acquisition. Caught up in a contentious conclusion, Diana Tindall realized that greater contextual information and stakeholder involvement in data analysis were needed.

Other challenges concern difficulties with managing organizational restructuring and sociopolitical change. E. Jane Davidson, Gail Vallance Barrington, and Lisa O'Reilly each discuss how institutional restructuring, management dysfunction, or changed priorities and policies can result, respectively, in scope creep and pro-bono work, unexpected contract terminations, and disagreements with findings.

Another set of difficulties concerns stakeholder relationships. Corey $\mathrm{Ne}$ whouse faced contradictory input from different stakeholders. Hallie Preskill mistakenly deemed key stakeholders as "secondary audiences." Rakesh Mohan navigated the fine line between responsiveness to stakeholders' priorities and 
independence from political influences in a public policy setting. Felix Muramutsa confronted a bilateral political issue when the reporting requirements of national governments and international donors clashed.

A fourth type stems from the relative employment position of the evaluator. As an external evaluator, Thomas Archibald designed an international evaluation plan remotely, only to be faced with the inability of the local evaluators to implement it within their budget and timeline. As an internal evaluator, Chris Lovato developed a logic model that initially did not have the program funders' support, which brought to light the fact that she had over-identified with the institution for which she worked.

A fifth theme concerns the mentorship and support available to evaluators. Emma Williams focuses on the significance of personal and peer support that is crucial to cope with professional commitments. Robert P. Shepherd describes placing students in an organization riddled with distrust and being unable to build a safe learning environment. Jan Noga trained field data collectors but failed to ground them in the logic of the approach they would be using.

Lastly, some challenges result from a lack of specific competencies. The lack of cultural-linguistic knowledge, as Isaac D. Castillo shows, or historic-political awareness, as Susan Igras reports, can stall a project. Hutchinson herself stresses the need to use investigative and communication tools appropriately, while Stephanie Evergreen explains that data visualizations are central to evaluation use but do not always go down well with critics.

This book is at its best when the authors move beyond the reflection of a specific challenge and take the opportunity to suggest improvements for the evaluation profession. Marla Steinberg recounts an occasion when the lack of fit between client and evaluator was painfully sharp and suggests that more guidelines be provided, not for evaluation commissioners to select appropriate evaluators but for evaluators to select and assess clients. Karen Snyder describes taking on an already-started project for which no reliable information had been gathered and proposes the use of the American Evaluation Association Guiding Principles to assess one's own evaluation experience. Similarly, Benoît Gauthier reflects on his initially narrow views of appropriate evaluation designs and interrogates the continued utility of program-centred logic models; he stresses the value of casual models, theories of change, and strategies that account for context and the complex systems in which the programs under evaluation are situated. Throughout the book, the reader will thus find evidence of a vibrant and shifting profession.

The authors often assume responsibility for the evaluation mistake or challenge. A recurring theme is the failure to see the "red flags" and suddenly hitting a roadblock. However, a close reading of the stories suggests that no matter the level of experience and preparation, broader processes-such as differing project visions, lack of evaluation champions, high staff turnover, or fraught politics-most often shape the circumstances and progression of the failures. It would be worthwhile to pursue a follow-up volume that examines in more detail, and explores how best to navigate, the broader conditions in which evaluation practitioners find themselves. 
Two things stand out most from this book. One is that this work requires skilled professionals who must be well versed in both technical (e.g., designing evaluation plans, using a wide range of methods, managing and budgeting projects) and soft competencies (e.g., negotiation, communication, interpersonal skills, adaptability). This realization will give the reader a strong admiration for the profession. A second insight is that unexpected challenges can happen to anyone. This awareness will reassure those new to the field that self- and shared reflection of the trials, embarrassments, and also triumphs of one's practice will help one's skillset grow.

Ultimately, this is an encouraging volume that provides readers with honest considerations and concrete ideas for moving forward. It reads as an informal conversation with a group of trusted mentors willing to share their vulnerable moments to help the reader walk the professional evaluation path. For that reason, this book will be of particular interest and use to students, early career evaluators, and seasoned professionals alike who are looking to sharpen their practice. 